\title{
High temperature indentation creep tests on anhydrite - a promising first look
}

\author{
D. Dorner ${ }^{1}$, K. Röller ${ }^{1, \dagger}$, and B. Stöckhert ${ }^{1}$ \\ ${ }^{1}$ Institute of Geology, Mineralogy and Geophysics, Ruhr University, Bochum, Germany \\ $\dagger$ Deceased \\ Correspondence to: D. Dorner (dorothee.dorner@freenet.de) and B. Stöckhert (bernhard.stoeckhert@rub.de)
}

Received: 29 September 2013 - Published in Solid Earth Discuss.: 19 November 2013

Revised: 5 May 2014 - Accepted: 23 June 2014 - Published: 12 August 2014

\begin{abstract}
Indentation creep tests are established in materials engineering, providing information on rheology, deformation mechanisms, and related microstructures of materials. Here we explore the potential of this method on natural, polycrystalline anhydrite. The tests are run at atmospheric pressure, temperatures between 700 and $920^{\circ} \mathrm{C}$, and reference stresses between 7 and $30 \mathrm{MPa}$. An activation energy $Q$ of $338 \mathrm{~kJ} \mathrm{~mol}^{-1}$ and a stress exponent $n$ of 3.9 are derived. Deformation is localized into shear zones bounding a less deformed approximately conical plug underneath the indenter. Shear zone microstructures reveal inhomogeneous crystalplastic deformation, subgrains, and extensive strain-induced grain boundary migration, while mechanical twinning appears not to be activated. Microstructure and mechanical data are consistent with deformation by dislocation creep.
\end{abstract}

\section{Introduction}

Deformation experiments on rocks and minerals provide information on material properties, deformation mechanisms, rheology, and related microfabrics (e.g. Schmid, 1982; Karato and Wenk, 2002). The mechanical data are used to extract flow law parameters, which are essential to predict the strength of crust and mantle at a wide range of conditions (e.g. Kohlstedt et al., 1995). Techniques used in experimental rock deformation are manifold (Tullis and Tullis, 1986). Triaxial compressional creep or constant strain rate tests are most widely applied using a wide range of different apparatus. Among those, gas pressure apparatus (Paterson 1970; Rybacki and Dresen, 2000) provide the greatest versatility and resolution, while solid medium (Griggs, 1967) or molten salt cell (Green and Borch, 1989; Rybacki et al., 1998) apparatus allow application of higher confining pressure, albeit with inferior stress resolution. High temperature uniaxial creep tests at atmospheric pressure are suitable for minerals such as olivine (e.g. Bai et al., 1991). Starting material can be natural (e.g. Schmid et al., 1977; Chopra and Paterson, 1981; Hirth and Tullis, 1994) or synthetic (e.g. Paterson and Luan, 1990; Renner et al., 2001) polycrystalline aggregates, requiring either the availability of rocks with required purity and grain size, or the possibility to synthesize polycrystalline aggregates with desired microstructure and sample dimensions.

As homogeneity of a sufficient material volume is one of the critical aspects, the use of small samples and uncomplicated preparation techniques is desirable. For instance, indentation tests have been used to study pressure solution of halite and quartz (Gratier, 1993; Gratier et al., 1999, 2009) and glide controlled crystal-plastic deformation of pyroxenes (Dorner and Stöckhert, 2004). In materials engineering, indentation creep tests (Chu and Li, 1977; Li, 2002; Zaafarani et al., 2006) have been established as an alternative to conventional uniaxial creep tests using cylindrical samples. The principle of indentation creep testing is simple. A cylindrical indenter is pushed into the flat surface of a sample driven by a constant load, and displacement is measured as a function of time. Such tests provide information on rheology, deformation mechanisms, and related microstructures of materials (e.g. Yue et al., 2001; Li, 2002; Dorner et al., 2003; Riccardi and Montanari, 2004). Dorner et al. (2003) performed indentation creep tests on an engineering alloy with a complex microstructure and demonstrated that the creep parameters obtained from indentation creep and uniaxial creep 
experiments (Skrotzki et al., 1999) on identical material are in good agreement.

In experimental rock deformation, indentation creep tests provide a means to study the rheology of minerals that are difficult to synthesize and not available as natural single phase aggregates with appropriate purity and grain size to be used in conventional testing of cylindrical samples. Sample preparation is simple and the design of the creep rig comparatively straightforward, with a minimum of uncertainty in measured force and displacement as a function of time. Furthermore, details of deformation and related microfabrics can be inspected in thin sections of the intact punch and sample assembly after the experiment. Deformation around a cylindrical indenter during indentation creep is characterized by large strain and strain rate gradients, which evolve in time, thus rendering this type of deformation test suitable to compare microstructures and fabrics with those observed in rocks after highly inhomogeneous deformation.

The objectives of the present study are twofold. First, we explore whether indentation creep testing can principally be used to investigate the mechanical behaviour and microfabric evolution of rock-forming minerals, using anhydrite as a prospective model material. Second, we aim to investigate the mechanical behaviour of dry anhydrite at high temperature, low pressure, and low differential stress, apart from pressure conditions expected for tectonic deformation of evaporites buried at deeper crustal levels.

\section{Anhydrite}

The term anhydrite is used to denote both a mineral with composition $\mathrm{CaSO}_{4}$ and a rock essentially composed of that mineral. Massive anhydrite rock is widespread in evaporitic sedimentary series (e.g. Sarg, 2001), where it is transformed by dehydration from primary gypsum $\left(\mathrm{CaSO}_{4} \cdot 2 \mathrm{H}_{2} \mathrm{O}\right)$ during burial at moderate temperatures. In turn, it is again replaced by gypsum when in contact with groundwater. At metamorphic conditions, anhydrite is the stable mineral phase. The melting temperature at atmospheric pressure is quoted as $1450^{\circ} \mathrm{C}$ (Haynes, 2012).

As anhydrite crystals are of orthorhombic symmetry with two very similar cell parameters (e.g. Deer et al., 1985), the choice of space group and notation of the crystallographic axes in the literature is non-uniform. Following Hildyard et al. (2009), here we adopt standard space group $\mathrm{Cmcm}$ and the corresponding set-up of crystallographic axes, for clarity shown in Fig. 1 together with refractive indices and optical axes. In this case, $b$ axis $(6.238 \AA)$ corresponds to acute bisectrix, $a$ axis $(6.996 \AA)$ to obtuse bisectrix, and $c$ axis $(6.991 \AA)$ to optical normal (cell parameters after Cheng and Zussman, 1963). Birefringence is about 0.04. According to the adopted crystallographic set-up, cleavage (100) is quoted as perfect, (001) very good, and (010) good (Deer et al.,

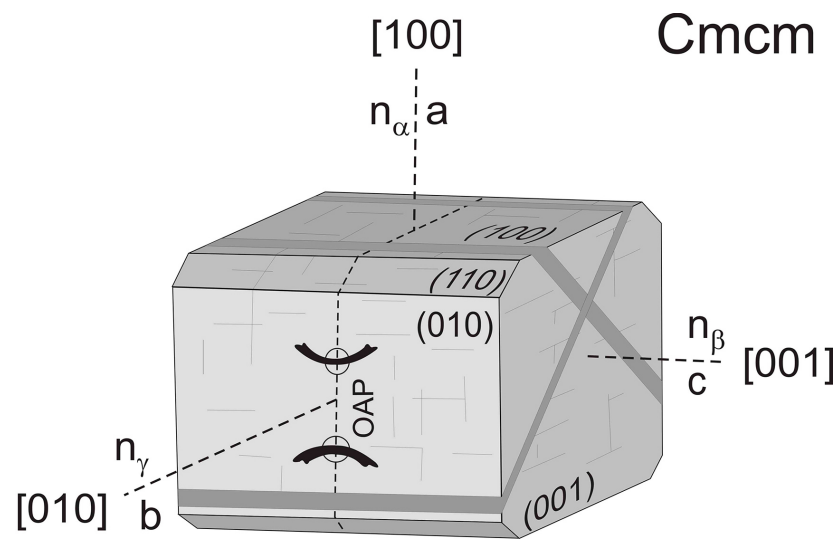

Figure 1. Anhydrite crystal structure, optical properties, and morphology modified after Tröger (1971). Miller indices hold for space group Cmcm following Hildyard et al. (2011). Note that this notation is different from that used in earlier studies on anhydrite rheology.

1985). Two sets of lamellar twins are oriented parallel to $\{110\}$.

Geological significance of anhydrite is twofold and intimately related to mechanical properties. First, low porosity and permeability qualifies anhydrite as cap rock for natural hydrocarbon accumulation as well as for technical storage of gas or nuclear waste in caverns. The sealing properties and their changes on human timescales have been extensively investigated in laboratory experiments (e.g. Handin and Hager, 1958; De Paola et al., 2009; Hangx et al., 2010a, b) at conditions relevant for geotechnical applications. Second, on longer time-scales and from tectonic point of view, mechanical weakness of anhydrite is frequently invoked to be responsible for localization of deformation in evaporitic horizons. For instance, basal detachment of the Jura mountains (Switzerland, France) located in Triassic evaporites controls the structural style of this spectacular fold belt (Müller and Briegel, 1977, 1978; Jordan, 1992).

Mechanical behaviour of anhydrite has therefore attracted significant attention and has been investigated in a number of experimental studies at elevated temperatures and pressures. Müller and Siemes (1974) as well as Müller et al. (1981) carried out deformation experiments at temperatures of up to $450{ }^{\circ} \mathrm{C}$ and confining pressures up to $0.3 \mathrm{GPa}$. Ramez (1976) reports on microstructures and crystallographicpreferred orientation in experimentally deformed samples. Dell'Angelo and Olgaard (1995) investigated the mechanical properties of fine-grained anhydrite rock in the regimes of diffusion creep and dislocation creep, establishing a composite flow law, which allows extrapolation of mechanical data to slow natural strain rates. Torsion experiments by Heidelbach et al. (2001) gave insight into the evolution of microstructure and texture under high shear strain. 
As impure anhydrite with various proportions of other minerals is widespread in nature, the deformation behaviour of polyphase rocks with anhydrite as major constituent was investigated by Ross et al. (1987) and Bruhn et al. (1999). Development of microstructures and textures in experimentally deformed anhydrite was studied by Bruhn and Casey (1997). In view of the highly strained nature of many natural anhydrite rocks, mechanical tests conducted in torsion provided unprecedented insight into the evolution of microstructure and crystallographic-preferred orientation (CPO), as demonstrated by Heidelbach et al. (2001) and Barnhoorn et al. (2005). Experimental results are compared to natural microstructures and CPO patterns (e.g. Marcoux et al., 1987; Jordan and Nüesch, 1989; Mainprice et al., 1993; Hildyard et al., 2009, 2011).

In the present study, we investigate the mechanical behaviour of relatively coarse-grained anhydrite at atmospheric pressure and dry conditions, applying higher temperatures, between 700 and $920^{\circ} \mathrm{C}$, and lower differential stress compared to previous experimental studies.

\section{Experimental setup}

\subsection{Starting material}

Anhydrite rock from the Gipswerk Moosegg quarry near Golling, Salzburg, Austria is used as starting material. These evaporites represent a locally occurring facies (Schorn and Neubauer, 2011) within the mid-Triassic Gutenstein formation, mainly composed of bituminous limestone and dolomites.

The anhydrite rock (sample \#14247, Mineralogical Collection, Ruhr University Bochum) is foliated and shows a combined shape-preferred orientation (SPO) and crystallographic-preferred orientation (CPO) with [001] parallel to lineation. It is composed of $>95 \%$ anhydrite, with minor dolomite, K-feldspar, phlogopite, hematite and accessory minerals including monazite. Distribution of second phases is inhomogeneous; in places, elongated patches of fine-grained dolomite aggregates occur. Otherwise, single crystals of other minerals are entirely embedded within anhydrite matrix. The grain size of anhydrite covers a wide range, the distribution being predominantly bimodal (Fig. 2). In most areas, grains with a diameter of 0.1 to $0.5 \mathrm{~mm}$, showing some low-angle grain boundaries and irregular high-angle grain boundaries, are surrounded by small grains with a diameter of about 0.01 to $0.05 \mathrm{~mm}$. The long axis of anisometric large grains is oriented parallel to the stretching lineation. Many large grains reveal some thin lamellar twins, albeit twin density is generally low (Fig. 2). Any modification of grain size and grain shape driven by interfacial free energy is not evident, though in places grain boundaries follow low index planes of one adjacent crystal, which qualify as unilaterally rational (Spry, 1969). In places, exceptionally large grains with a diameter exceeding $1 \mathrm{~mm}$ occur, sometimes in aggregates, which are characterized by predominantly rational low-index interfaces (Fig. 2). Despite a considerable CPO of the starting material, the scatter of orientation of individual crystals is large enough as to provide crystals with a wide spectrum of Schmid factors at the onset of deformation in the experiments, and thus a significant effect of CPO on mechanical results can be ruled out. Finally, based on microscopic inspection, porosity remains well below $1 \%$.

For the indentation tests, plane-parallel plates oriented normal to foliation and parallel to lineation were cut from the specimen. These samples measure about $20 \mathrm{~mm} \times 20 \mathrm{~mm}$ with a thickness of about $6 \mathrm{~mm}$. Regions with essentially pure anhydrite were selected, macroscopically identified by their uniform bright gray colour. The experiments were conducted with the indenter axis oriented parallel to foliation and normal to lineation (Fig. 3).

\subsection{Creep rig}

Indentation creep tests were performed using a conventional high temperature creep rig operated at atmospheric pressure, which allows testing at temperatures of up to $1200^{\circ} \mathrm{C}$. The apparatus follows the scheme originally designed by Kohlstedt and Goetze (1974), described in detail by Mackwell et al. (1990). It was used in experiments on olivine by Bai et al. (1991) and Jin et al. (1994), and on feldspar by Wang et al. (1996), for example. It consists of a load frame, pistons with load cell, sample assembly, furnace, displacement transducers, and a data acquisition system.

Differing from the conventional set-up with cylindrical specimens, here the plane parallel anhydrite plate is placed on an alumina spacer separating it from the lower piston (Fig. 4). The cylindrical alumina indenter to be driven into the sample, measuring $2.0 \mathrm{~mm}$ in diameter and $1.6 \mathrm{~mm}$ in height, is positioned in the centre of the specimen in order to minimize potential boundary effects. A second alumina spacer is placed between the indenter and the movable upper alumina piston, which transmits the axial load. The entire sample assembly is placed inside the tube furnace. Temperature is measured with a PtRh-Pt thermocouple next to the specimen.

Axial load is applied by a dead weight, which is a stack of steel plates resting on the upper piston (Fig. 4). A load cell measures the force acting on the indenter. Displacement is measured by two low-velocity displacement transducers (LVDT) coupled by alumina rods to the sample assemblage inside the furnace. One transducer records the displacement of the upper piston with respect to the lower piston, i.e. the progress of the indenter into the specimen, the other transducer measures length changes within the loading system to monitor effects of temperature changes (Fig. 4). Temperature, load, and displacement are recorded by a signal acquisition unit. 

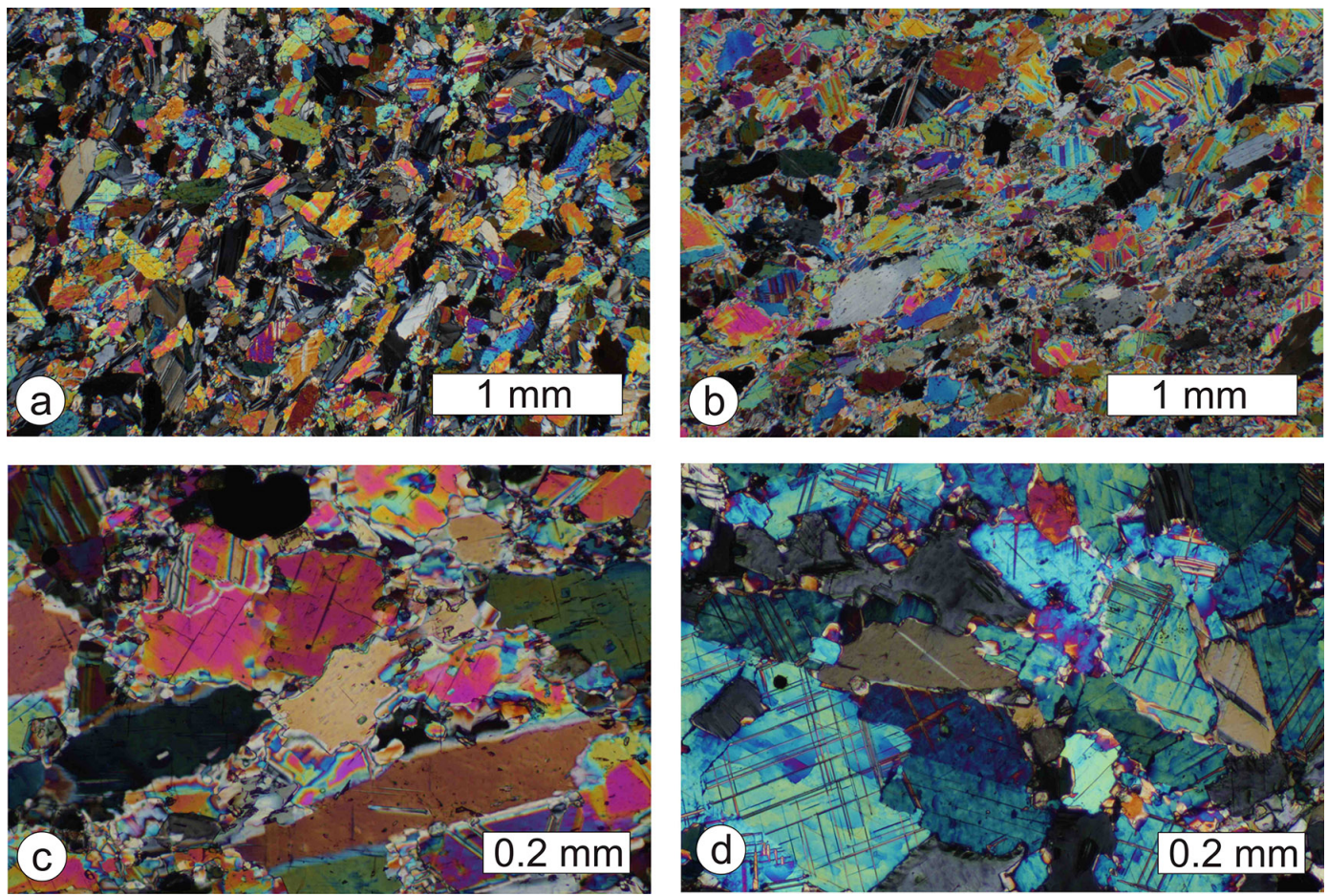

Figure 2. Microstructure of anhydrite rock from Gipswerk Moosegg (sample \#14247, Mineralogical Collection, Ruhr University Bochum) used as starting material (optical micrographs with crossed polarizers; thin section normal to stretching lineation); (a) and (b) examples revealing heterogeneity of material on mm-scale, with elongated grains parallel to foliation and variable grain size; (c) elongated large grains define foliation with irregular and sutured high-angle grain boundaries, surrounded by small recrystallized grains; (d) two sets of thin lamellar twins, discernible in many grains, reflect the preferred orientation of [001] (cf. Fig. 1) normal to the thin section and parallel to the lineation of the starting material.

\subsection{Experimental procedure}

The desired testing load is achieved by mounting the respective number of steel plates onto the holder on top of the upper piston. The specimen, indenter, and upper and lower spacer are assembled on the lower piston. The sample assembly on the lower piston is lifted into the centre of the furnace and the upper piston carefully lowered onto the sample. Afterwards the assembly is heated up at a rate of $1 \mathrm{~K} \mathrm{~min}^{-1}$. After the testing temperature is reached, the upper piston with the load is released and the indenter slowly driven into the specimen for time periods of a few hours to several days, depending on temperature and load applied, until the final indentation depth of usually 1 to $2 \mathrm{~mm}$ is reached. At this point the load is removed, the furnace switched off, and the specimen slowly cooled to room temperature. After the experiment, the specimen with the indenter in place is cut with a diamond saw in a plane, which is oriented normal to the lineation of the starting material and contains the indenter axis. This standard orientation shows only a moderate grain-shape anisometry of the starting material, rendering the modification during indentation more obvious. Polished thin sections are prepared, allowing microscopic inspection of the entire specimen-indenter assembly and investigation of microfabrics by optical microscopy.

\subsection{Evaluation of creep data}

A total of 17 runs were performed (Table 1), including one (AF 2) performed as a temperature stepping test. Data acquired during each experiment include temperature $T$, force $F$, and displacement $h$ as a function of time. The creep curves, i.e. indentation depth $h$ versus time, are characterized by a transient stage, followed by a steady-state stage with an approximately constant indentation rate, until the experiment was terminated. Examples are displayed in Fig. 5. Indentation rates transformed into uniaxial strain rates used for the derivation of the flow law parameters were taken from the steady-state part of the creep curves.

During the indentation of the cylindrical punch into the sample, stress field and strain rate field are complex in nature and evolve with time. Earlier studies (e.g. Yu and Li, 1977; Chu and Li, 1979, 1979; Yu et al., 1985; Hyde et al., 1993; Tasnádi et al., 1988; Chiang and Li, 1994; Dorner et al., 2003) have shown that both net section stress $\sigma_{\text {net }}$ and indentation rate $\dot{h}$ can be converted into equivalent values, termed uniaxial reference stress $\sigma$ and uniaxial reference strain rate 


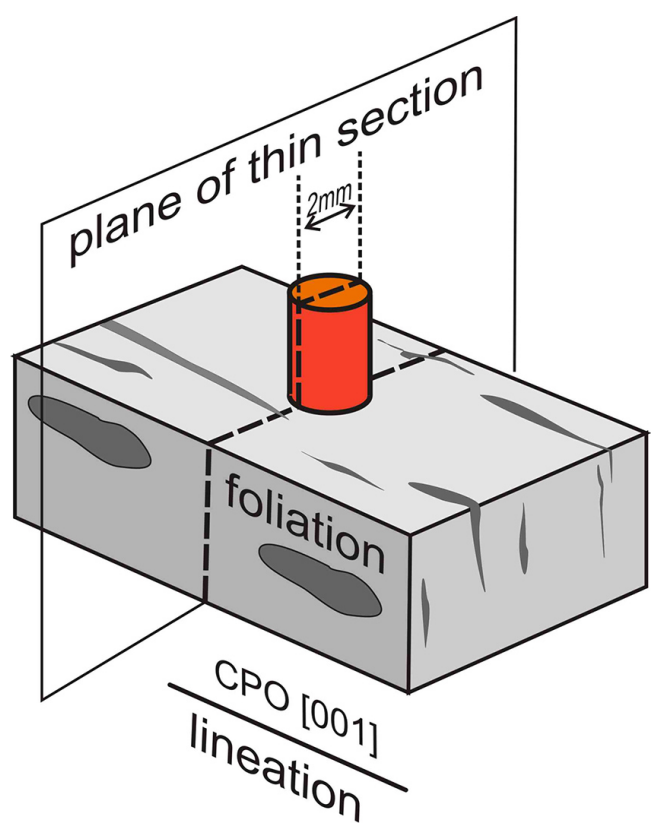

Figure 3. Scheme showing orientation of indenter axis with respect to foliation and lineation of the starting material, which shows CPO of [001] (cf. Fig. 1) parallel to lineation. Thin sections of experimentally deformed samples including the indenter are oriented normal to lineation.

$\dot{\varepsilon}$, respectively. The net section stress $\sigma_{\text {net }}$ is defined as the load $F$ acting on the indenter divided by the circular indenter area $A$ :

$\sigma_{\text {net }}=F / A$.

Net section stress $\sigma_{\text {net }}$ is converted into uniaxial reference stress ("reference stress") $\sigma$ according to

$\sigma=c_{1} \cdot \sigma_{\text {net }}$,

with a conversion factor $c_{1}$. Similarly, indentation rate $\dot{h}$ is converted into uniaxial reference strain rate ("reference strain rate") $\dot{\varepsilon}$ according to

$\dot{\varepsilon}=c_{2} \cdot \frac{\dot{h}}{2 r}$,

with indenter diameter $d=2 r$ and conversion factor $c_{2}$. Here we use conversion factors $c_{1}$ of 0.296 and $c_{2}$ of 0.755 derived according to finite element calculations by Hyde et al. (1993).

After converting the experimentally acquired net section stress and indentation rate into reference stress and reference strain rate, respectively, a flow law of the following form was derived for anhydrite:

$\dot{\varepsilon}=A \cdot \sigma^{n} \cdot \exp \left(-\frac{Q}{R \cdot T}\right)$,

\section{(a) conventional}

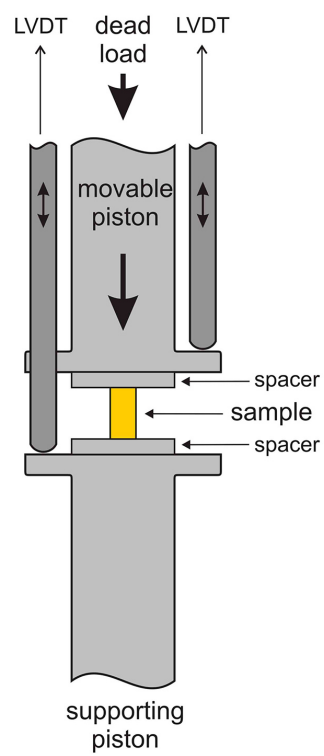

(b) indentation

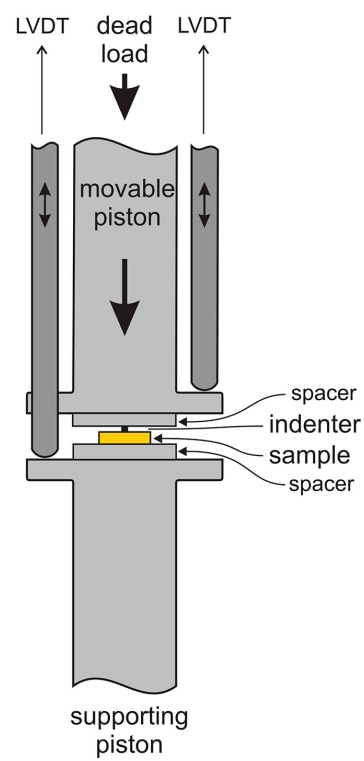

Figure 4. Scheme of creep rig. Panel (a) - conventional configuration with a cylindrical sample. Panel (b) - configuration used in indentation creep experiments with a small cylindrical indenter thrust into a plane-parallel plate of sample material. Apart from sample assembly, the entire set-up is identical for both approaches.

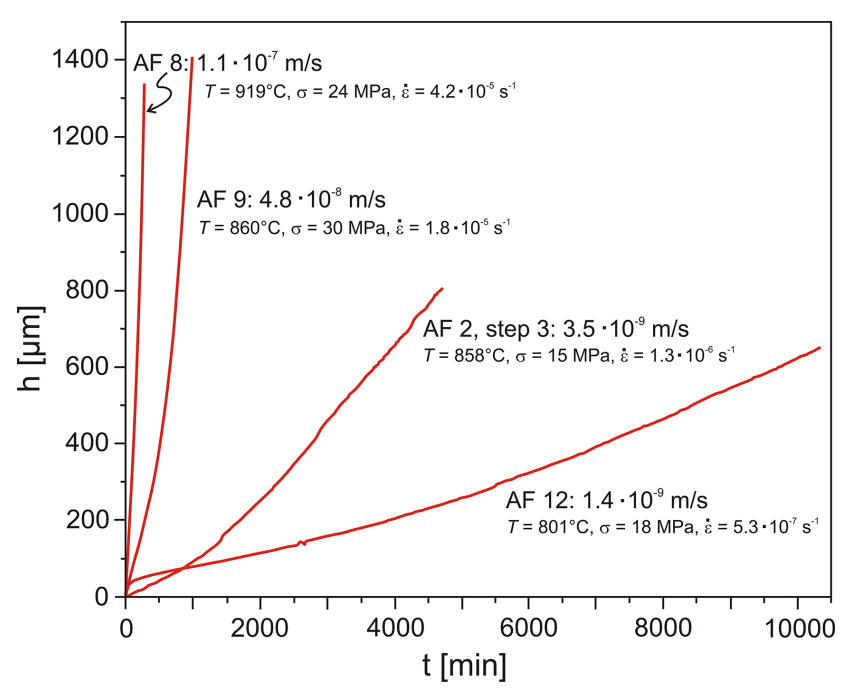

Figure 5. Exemplary creep curves (displacement $h$ versus time $t$ ) for four of the experiments listed in Table 1. After a transient stage lasting up to 3 to 4 days, steady state is achieved, with a slope controlled by load and temperature.

where $\dot{\varepsilon}$ denotes strain rate, $A$ pre-exponential factor, $\sigma$ differential stress (= reference stress), $n$ stress exponent, $Q$ activation energy, $R$ universal gas constant, and $T$ temperature.

The stress exponent $n$ is the slope of a linear fit in a $\log$ $\log$ plot of strain rate $\dot{\varepsilon}$ versus reference stress $\sigma$ at constant 


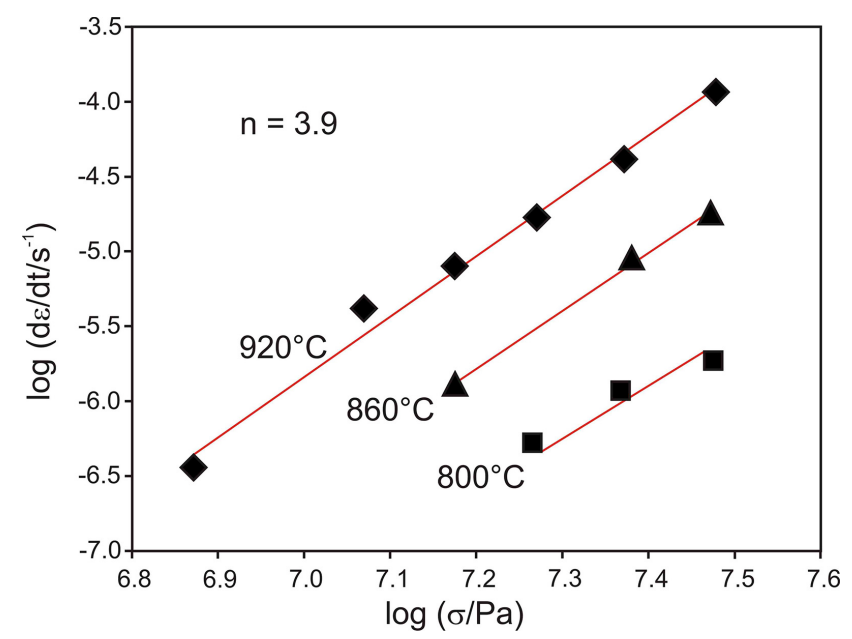

Figure 6. Derivation of stress exponent $n$ in a log-log plot of reference strain rate $\dot{\varepsilon}$ versus reference flow stress $\sigma$ at various constant temperatures. A mean stress exponent of $n=3.9$ was derived from creep data obtained at temperatures of 800,860 , and $920,{ }^{\circ} \mathrm{C}$.

temperatures (Fig. 6). The activation energy $Q$ was derived from an Arrhenius plot of strain rate $\dot{\varepsilon}$ versus inverse temperature at constant stresses (Fig. 7).

\section{Results}

\subsection{Mechanical data}

The indentation creep experiments on polycrystalline anhydrite were performed at temperatures between 708 and $920^{\circ} \mathrm{C}$ (Table 1). The load was varied between 79 and $319 \mathrm{~N}$. For the indenter diameter of $2.0 \mathrm{~mm}$, this corresponds to net section stresses between 24 and $102 \mathrm{MPa}$. Using the stress conversion according to Equation 1, uniaxial reference stresses between 7 and $30 \mathrm{MPa}$ were derived (Table 1). The duration of creep tests was between $5 \mathrm{~h}$ and 20 days. The indentation rates obtained from steady-state sections of creep curves range between $10^{-11} \mathrm{~m} \mathrm{~s}^{-1}$ and $10^{-7} \mathrm{~m} \mathrm{~s}^{-1}$. After strain rate conversion with Eq. (2), the reference strain rates are in the range of $10^{-9} \mathrm{~s}^{-1}$ to $10^{-5} \mathrm{~s}^{-1}$ (Table 1).

Based on the flow law of the form given in Eq. (3), a stress exponent $n$ of 3.9 (Fig. 6), an activation energy $Q$ of $338 \mathrm{~kJ} \mathrm{~mol}^{-1}$ (Fig. 7), and a pre-exponential factor $A$ of $4.8 \times 10^{-19} \mathrm{~Pa}^{-3.9} \mathrm{~s}^{-1}$ were determined for the data set given in Table 1. Accordingly, the flow law for polycrystalline anhydrite at atmospheric pressure can be written as

$\dot{\varepsilon}=4.8 \times 10^{-19} \mathrm{~Pa}^{-3.9} \mathrm{~s}^{-1} \cdot \sigma^{3.9} \cdot \exp \left(-\frac{338 \mathrm{~kJ} \mathrm{~mol}^{-1}}{R \cdot T}\right)$.

The predicted relationship between reference strain rate and reference stress for the temperature range covered by the ex-

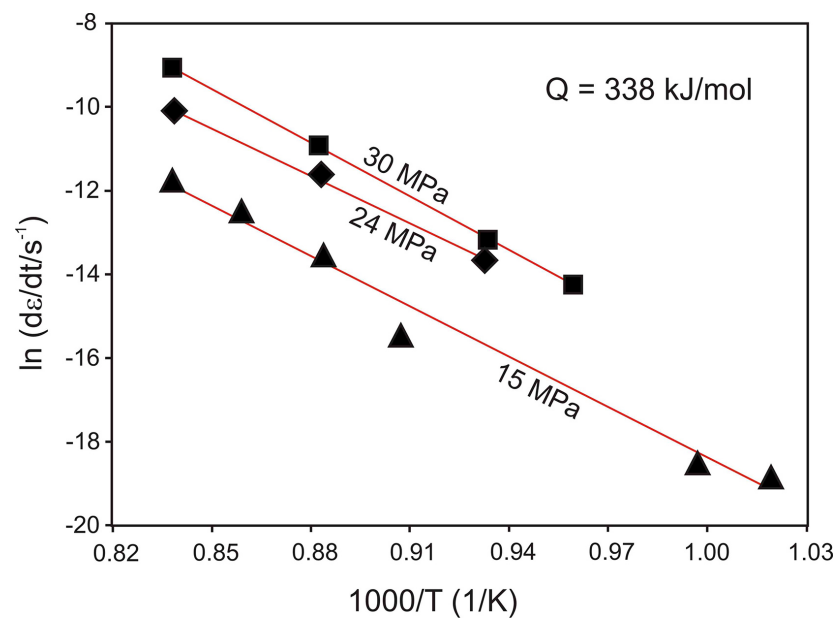

Figure 7. Derivation of activation energy $Q$ in an Arrhenius plot of reference strain rate $\dot{\varepsilon}$ versus inverse temperature $1 / T$ at various constant stresses. A mean activation energy of $Q=338 \mathrm{~kJ} \mathrm{~mol}^{-1}$ was derived from creep data obtained at reference stresses $\sigma$ of 15 , 24 , and $30 \mathrm{MPa}$.

periments, including the data points for the individual runs, is depicted in Fig. 8.

\subsection{Microfabrics}

A sample plate with an alumina indenter in place, as recovered after an experiment and prior to thin section preparation, is depicted in Fig. 9a. The scan of the thin section prepared from experiment AF 13 (Table 1) reveals the effects of indentation on the sample scale (Fig. 9b). Rotational symmetry is expected as a first approximation. The originally plane upper surface of the sample is slightly depressed around the indenter, forming a circular moat (Fig. 9b and c) with a diameter approximately corresponding to three times that of the indenter. Along the flanks of the cylindrical indenter, a circular wedge-shaped gap emerging from the edge of the protruding indenter has developed, referred to as crevasse in the following (Fig. 9b and c); the wedge angle is about $2^{\circ}$. The transition between crevasse and moat is sharp. At given initial porosities well below $1 \%$, any contribution of compaction to strain achieved in indentation must be negligible. It is therefore assumed that the volume displaced by the indenter is compensated by distributed dilation on the sample scale, which cannot be precisely measured. The ratio of displaced volume to total sample volume is typically about $1.3 \times 10^{-3}$. Assuming an extension parallel to the long sides of the sample, the length change would amount to less than $0.01 \mathrm{~mm}$.

Despite complex microstructure of the starting material (Fig. 2), the modification of microstructure and development of CPO related to indentation are well discernible in Fig. 9b. A conspicuous region with similar interference colors of anhydrite grains mantles a conical region, within which the 
Table 1. Indentation creep data for polycrystalline anhydrite. For each creep test, the temperature $T$, the homologeous temperature $T / T_{\mathrm{m}}$, the load $F$, the net section stress $\sigma_{\text {net }}$, the uniaxial reference stress $\sigma$, the normalized reference stress $\sigma / G$ with shear modulus $G$, the indentation rate $\dot{h}$, and the uniaxial reference strain rate $\dot{\varepsilon}$ rate are listed. Sample AF 2 was deformed at three different temperatures, while the load was kept constant.

\begin{tabular}{lccrrrccc}
\hline $\begin{array}{l}\text { Creep } \\
\text { test }\end{array}$ & $\begin{array}{c}T \\
\left({ }^{\circ} \mathrm{C}\right)\end{array}$ & $T / T_{\mathrm{m}}$ & $\begin{array}{r}F \\
(\mathrm{~N})\end{array}$ & $\begin{array}{r}\sigma_{\text {net }} \\
(\mathrm{MPa})\end{array}$ & $\begin{array}{r}\sigma \\
(\mathrm{MPa})\end{array}$ & & $\begin{array}{l}\sigma \\
\left(\mathrm{m} \mathrm{s}^{-1}\right)\end{array}$ & $\begin{array}{c}\dot{\varepsilon} \\
\left(\mathrm{s}^{-1}\right)\end{array}$ \\
\hline AF 1 & 708 & 0.57 & 162 & 51 & 15 & $5.1 \times 10^{-4}$ & $1.7 \times 10^{-11}$ & $6.4 \times 10^{-9}$ \\
AF 2 & 730 & 0.58 & 159 & 51 & 15 & $5.0 \times 10^{-4}$ & $2.4 \times 10^{-11}$ & $9.0 \times 10^{-9}$ \\
AF 2 & 829 & 0.64 & 159 & 51 & 15 & $5.0 \times 10^{-4}$ & $5.1 \times 10^{-10}$ & $1.9 \times 10^{-7}$ \\
AF 2 & 858 & 0.66 & 159 & 51 & 15 & $5.0 \times 10^{-4}$ & $3.5 \times 10^{-9}$ & $1.3 \times 10^{-6}$ \\
AF 3 & 891 & 0.68 & 160 & 51 & 15 & $5.0 \times 10^{-4}$ & $1.0 \times 10^{-8}$ & $3.8 \times 10^{-6}$ \\
AF 4 & 920 & 0.69 & 159 & 51 & 15 & $5.0 \times 10^{-4}$ & $2.1 \times 10^{-8}$ & $7.9 \times 10^{-6}$ \\
AF 5 & 920 & 0.69 & 319 & 102 & 30 & $1.0 \times 10^{-3}$ & $3.1 \times 10^{-7}$ & $1.2 \times 10^{-4}$ \\
AF 6 & 920 & 0.69 & 125 & 40 & 12 & $3.9 \times 10^{-4}$ & $1.1 \times 10^{-8}$ & $4.2 \times 10^{-6}$ \\
AF 7 & 919 & 0.69 & 198 & 63 & 19 & $6.2 \times 10^{-4}$ & $4.4 \times 10^{-8}$ & $1.7 \times 10^{-5}$ \\
AF 8 & 919 & 0.69 & 250 & 80 & 24 & $7.9 \times 10^{-4}$ & $1.1 \times 10^{-7}$ & $4.2 \times 10^{-5}$ \\
AF 9 & 860 & 0.66 & 315 & 100 & 30 & $9.9 \times 10^{-4}$ & $4.8 \times 10^{-8}$ & $1.8 \times 10^{-5}$ \\
AF 10 & 798 & 0.62 & 317 & 101 & 30 & $1.0 \times 10^{-3}$ & $5.0 \times 10^{-9}$ & $1.9 \times 10^{-6}$ \\
AF 11 & 769 & 0.60 & 318 & 101 & 30 & $1.0 \times 10^{-3}$ & $1.7 \times 10^{-9}$ & $6.4 \times 10^{-7}$ \\
AF 12 & 801 & 0.62 & 196 & 62 & 18 & $6.2 \times 10^{-4}$ & $1.4 \times 10^{-9}$ & $5.3 \times 10^{-7}$ \\
AF 13 & 799 & 0.62 & 248 & 79 & 23 & $7.8 \times 10^{-4}$ & $3.1 \times 10^{-9}$ & $1.2 \times 10^{-6}$ \\
AF 14 & 920 & 0.69 & 79 & 24 & 7 & $2.5 \times 10^{-4}$ & $9.7 \times 10^{-10}$ & $3.7 \times 10^{-7}$ \\
AF 18 & 859 & 0.66 & 255 & 80 & 24 & $8.0 \times 10^{-4}$ & $2.4 \times 10^{-8}$ & $9.1 \times 10^{-6}$ \\
\hline
\end{tabular}

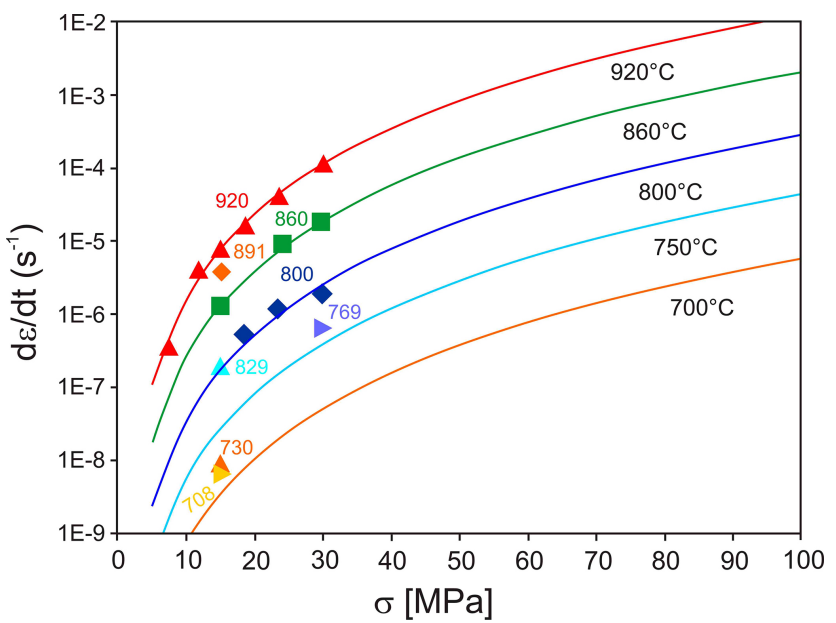

Figure 8. Experimental data obtained at various temperatures between 700 to $920^{\circ} \mathrm{C}$ and adapted flow law displayed as reference strain rate as a function of reference stress.

original microstructure apparently has remained more or less unmodified. The impression that the geometry of this passive cone may be somewhat different for different experiments is probably a consequence of slight variable deviation of the section plane from a true median cut. According to principles of conic sections, only a precise median cut containing the apex of the cone provides a triangular section showing the true apex angle. With increasing shift of the section plane from the apex, the section assumes the shape of a hyperbola with increasing apparent angle between the limbs. The apparent shape is therefore highly sensitive to position, which cannot be perfectly controlled during preparation.

The mantling shear zones reveal an inner narrow transition zone towards the passive cone, and smoothly grade outwards into the unaffected matrix. Within the shear zones, microstructure is characterized by an elongated grain shape and some degree of grain-size reduction by dynamic recrystallization. High-angle grain boundaries are sutured and lowangle grain boundaries, on an optical scale, are discernible in larger grains. Along the crevasse, a well-defined zone about $0.1 \mathrm{~mm}$ wide is characterized by small grain size. With respect to mechanical twins, no obvious contrast is observed between the region affected by indentation and the original microstructure. These microstructures are developed in a similar manner for all experiments, as demonstrated in Fig. 10 using AF 7, AF 8, AF 9, and AF 10 (Table 1) as examples. Details of the microstructure that developed near the edge of the indenter in experiment AF 3 are shown in Fig. 11. Figure 12 shows small-scale microstructural features that developed during indentation in the comparatively high stress experiment AF 10 (reference stress $30 \mathrm{MPa}$ ). In particular, it demonstrates the systematic absence of lamellar twins in the recrystallized shear zone. 
(a)

(b)
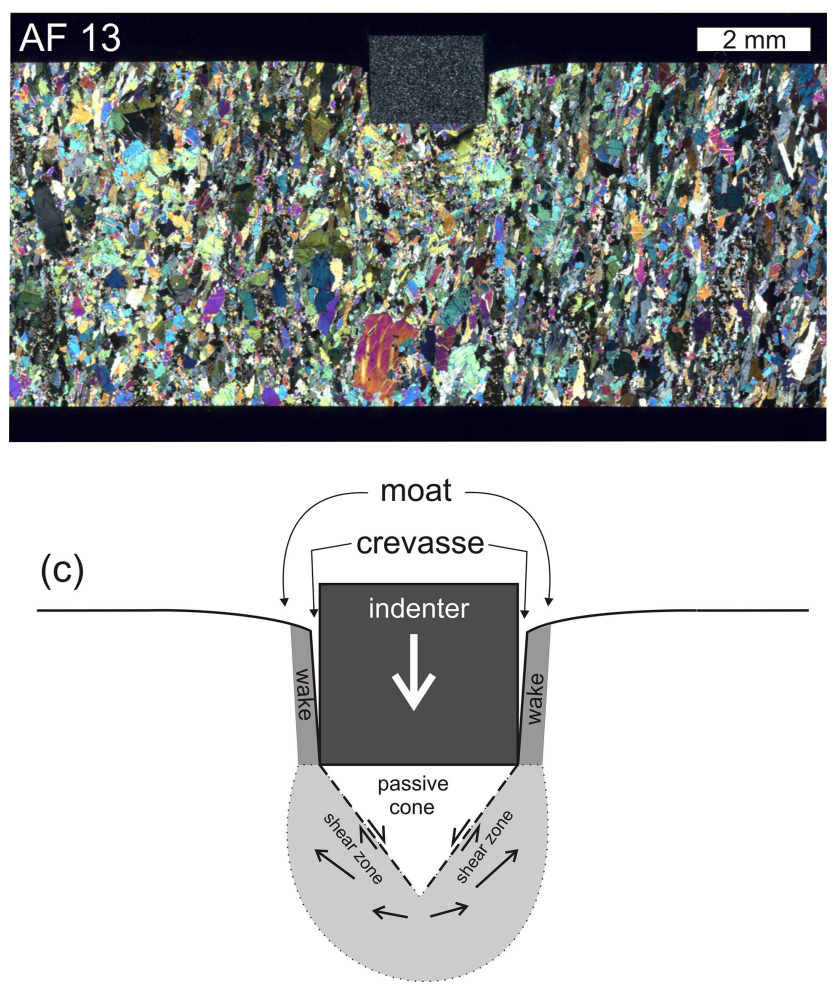

Figure 9. Panel (a) - photography of specimen with alumina indenter in place; (b) scan of thin section from experiment AF 13 showing modification of anhydrite microfabric around the alumina (fine-grained; low interference colours) indenter; median cut normal to lineation of the starting material; (c) scheme showing moat, crevasse, and passive cone bound by shear zones underneath the indenter; rotational symmetry is inferred.

\section{Discussion}

\subsection{Local deformation history}

The history of deformation within a volume element of material in the ambit of the indenter is not uniform both in orientation of stress and strain rate tensor, and the respective magnitudes. Deformation stages with evolving characteristics are continuously superimposed onto each other. Shear zones form in front of the indenter, separating the passive cone from surrounding deformed material. At the envelope of the cone, local deformation is expected to involve both a component of simple shear in a plane coplanar with the indenter axis, and a component of pure shear with the ex- tension tangential to the cone surface in a plane normal to the indenter axis (Fig. 13). Stress concentration is predicted around the circular edge of the indenter (e.g. Riccardi and Montanari, 2004), leading to the highest deformation rates. After a volume element has passed the indenter edge, deformation ceases, and the hitherto-developed microstructure remains largely preserved due to mechanical decoupling across the crevasse (Figs. 9, 10, 11 and 12). The stage of highstress flow around the edge of the indenter leaves a wake of strongly deformed material. Within this wake (Figs. 10, 11 and 12), despite decoupling, even in high temperature experiments there seems to be no significant microstructural modification and increase in grain size on the optical scale. Further deformation is minor, related to progressive widening of the annular space surrounding the cylindrical indenter, giving rise to the wedge-shape of the crevasse in the cross section (Figs. 10, 11 and 12).

\subsection{Microfabrics}

Terminal microfabrics and CPO result from a history of deformation with superimposed stages of differing stress state and strain geometry. Interpretation of CPO in terms of activated glide systems (e.g. Hildyard et al., 2011) therefore remains beyond the scope of the present paper. Also, in the coarse-grained material used here, the number of grains within a volume element is insufficient to provide a statistically relevant base. For fine-grained material combined with numerical simulation of local strain history we envisage a large potential for future work.

Apart from complex local deformation history, interpretation of microfabrics related to indentation is hampered by inhomogeneous grain size and pronounced combined SPO and $\mathrm{CPO}$ of the starting material (Fig. 2). This makes isolation of specific features related to indentation creep ambiguous on the small scale. On the larger scale, however, deformation localized into shear zones delineating a largely undeformed neutral cone in in front of the indenter is conspicuous when observed by polarizing microscopy at low magnification (Figs. 9, 10). These shear zones represent the inner borders of a wider envelope of deformation waning outwards into the surrounding material. Observed by polarizing microscopy, similar extinction (Fig. 10) within grain aggregates in the shear zone and envelope demonstrate the evolution of $\mathrm{CPO}$ related to indentation. In combination with elongated grain shape (Fig. 12), low-angle grain boundaries discernible in larger grains (Fig. 12c), serrated high-angle grain boundaries (Fig. 12c), and overall grain-size reduction (Fig. 12), the microfabrics of the shear zones (Figs. 10 and 12) indicate crystal-plastic deformation with dynamic recrystallization and recovery during indentation.

Despite intense crystal-plastic deformation, lamellar twins after $\{110\}$ are not observed to increase in frequency related to indentation and, in particular, not close to the indenter edge (Fig. 12c) or in the wake (Fig. 12d). Beyond 


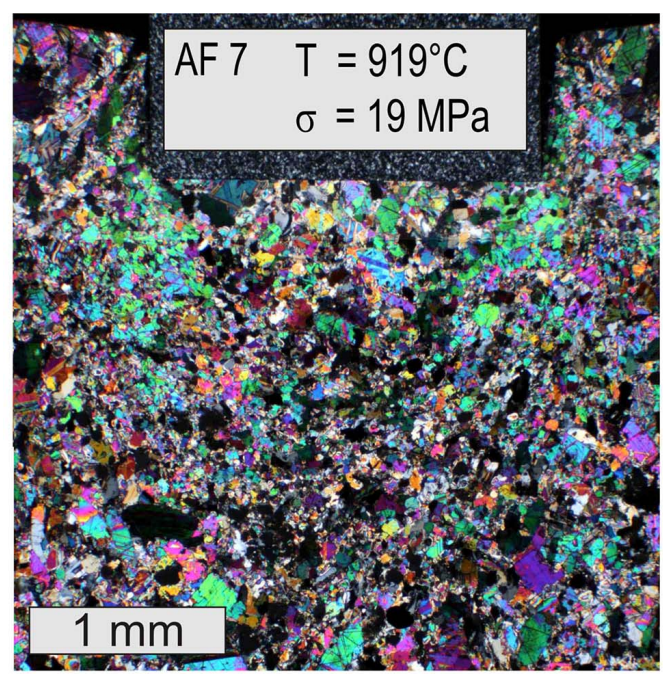

(a)

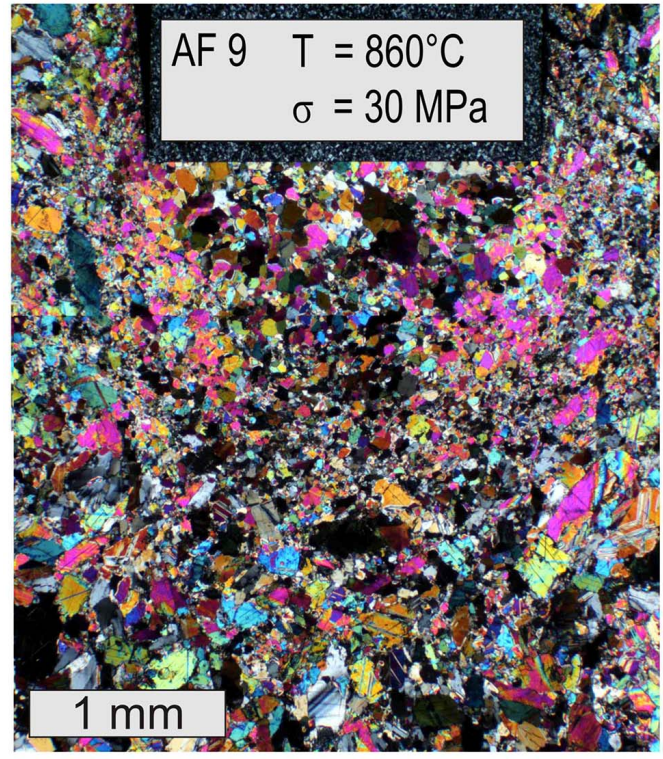

(c)

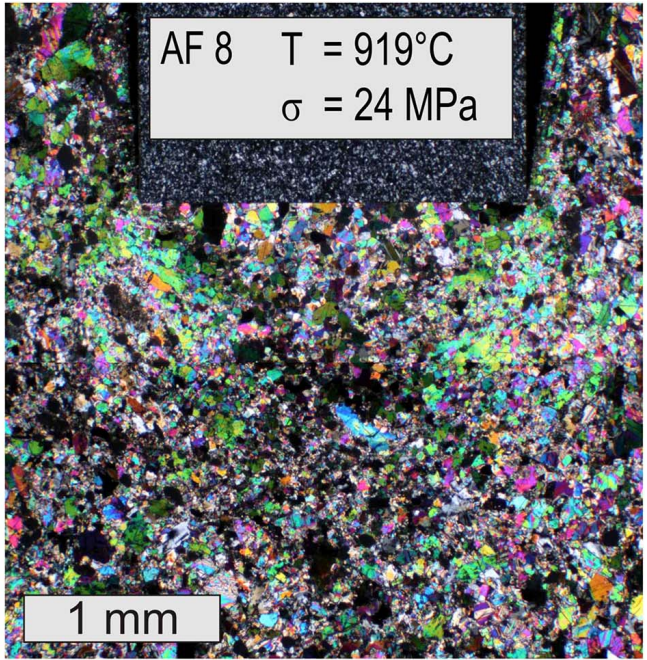

(b)

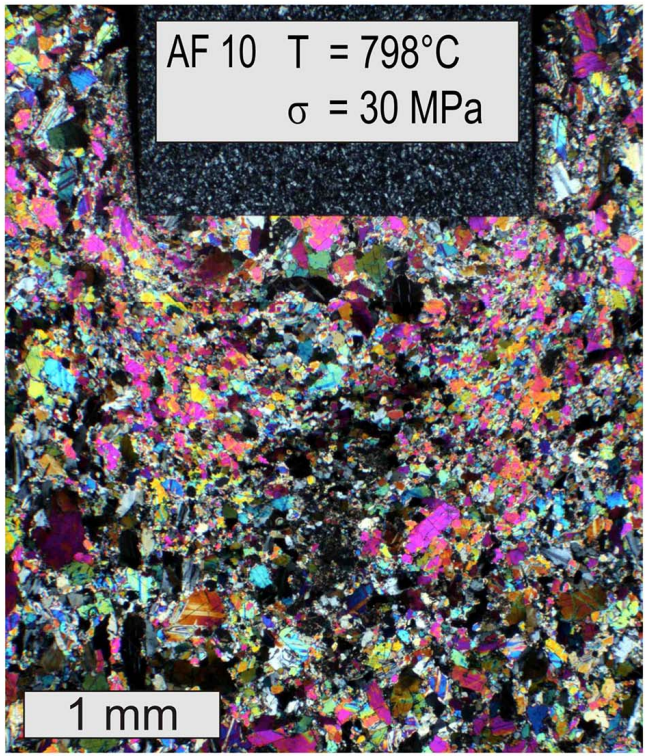

(d)

Figure 10. Optical micrographs showing anhydrite microstructures developed beneath the indenter for experiments at different temperatures and reference stresses: (a) $\mathrm{AF} 7: 919^{\circ} \mathrm{C}, 19 \mathrm{MPa}$; (b) $\mathrm{AF} 8: 919^{\circ} \mathrm{C}, 24 \mathrm{MPa}$; (c) $\mathrm{AF} 9: 860^{\circ} \mathrm{C}, 30 \mathrm{MPa}$; (d) $\mathrm{AF} 10: 798^{\circ} \mathrm{C}, 30 \mathrm{MPa}(\mathrm{see}$ Table 1 for details). Modification of microstructure and development of CPO related to indentation in deformation zone mantling undeformed central cone (Fig. 9c) is well discernible.

the shear zone mantling the passive cone, observed twins correspond to those already present in the starting material (Fig. 2), both in morphology and density (e.g. Rowe and Rutter, 1990), and thus appear to be inherited. Also, there is no evidence of twin boundary migration (e.g. Rutter, 1995; Dell'Angelo and Olgaard, 1995; Bestmann and Prior, 2003), even at the highest temperatures.

Mechanical twinning is predicted to take place when the critical resolved shear stress (CRSS) on the respective plane and in the crystallographically defined direction is reached (Tullis, 1980). For minerals with high CRSS like pyrox- enes (Kolle and Blacic, 1982; Orzol et al., 2003), mechanical twins provide a useful paleopiezometer to infer peak stresses attained in the past (e.g. Trepmann and Stöckhert, 2001). While CRSS for twinning is generally expected to be rather insensitive to temperature, Kern and Richter (1985) propose, in the case of anhydrite, that twinning may be facilitated at elevated temperatures, according to experimental results obtained by Müller et al. (1981). Also, Mainprice et al. (1993) suspect initiation of twinning to involve a thermally activated process. In contrast, our experiments conducted at temperatures exceeding the range previously 

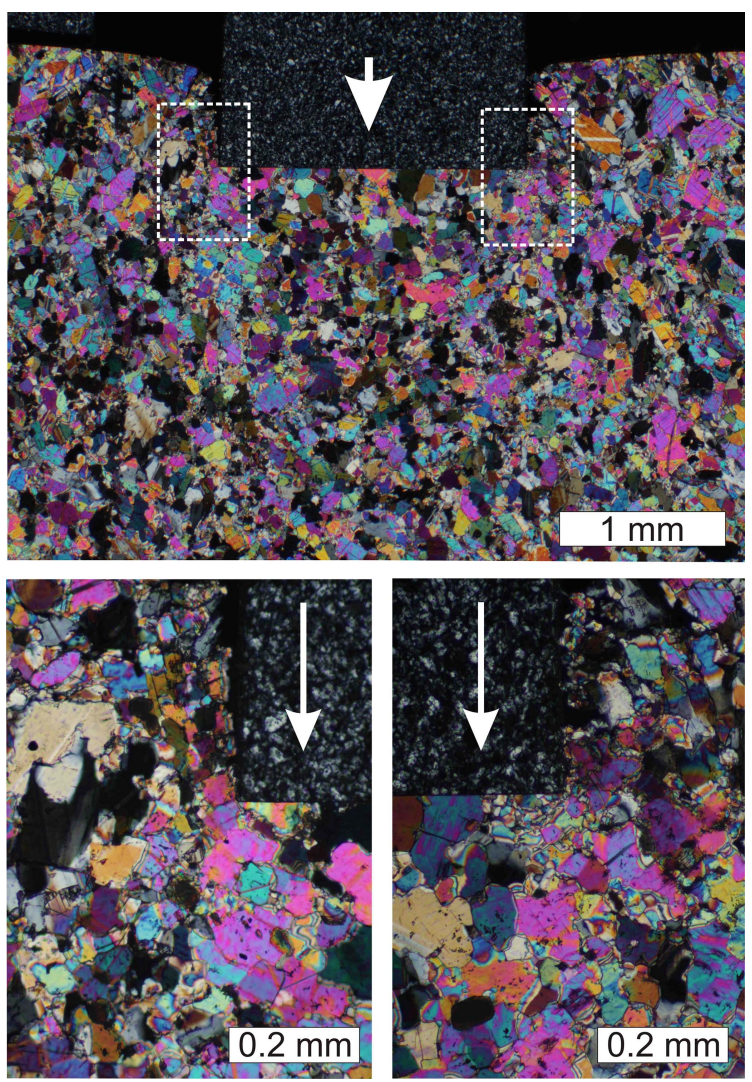

Figure 11. Close up view of anhydrite microstructure developed at the site of stress concentration along the circular edge of the indenter, and preservation within the wake flanking the crevasse (cf. Fig. 9c). Experiment AF 3: $891^{\circ} \mathrm{C}, 15 \mathrm{MPa}$ reference stress.

covered by laboratory experiments on anhydrite do not show evidence of mechanical twinning, not even at sites of stress concentration (Figs. 11, 12c and d). We therefore conclude that the CRSS for mechanical twinning is generally not reached in our experiments at nominal reference stresses of 7 to $30 \mathrm{MPa}$, despite stress amplification at the indenter edge. There, the small size of recrystallized grains (Figs. 11 and 12) may inhibit twin formation or the twins may remain undetected on the optical scale. As such, a tendency of twinning to become more effective towards higher temperatures cannot be confirmed, not being observed to play a role even at temperatures of $920^{\circ} \mathrm{C}$. A possible reason for this is that all our experiments are conducted at lower nominal stress compared to those of Müller et al. (1981) and Dell'Angelo and Olgaard (1995).

\subsection{Deformation regime}

The microstructure characterized by elongated grain shape with sutured high-angle grain boundaries, small new grains, and low-angle grain boundaries indicates deformation in the regime of dislocation creep, controlled by recovery and recrystallization (e.g. Schmid, 1982; Poirier, 1985; Karato,
2008). This regime is expected for the given experimental conditions, normalized over melting temperature $T$ and shear modulus $G$. As the melting temperature of anhydrite at atmospheric pressure is quoted as about $1723 \mathrm{~K}$ (Haynes, 2012), homologous temperatures $T / T_{\mathrm{m}}$ amount to 0.57 to 0.69 for the experimental conditions applied in this study. In general, homologous temperatures exceeding 0.4 to 0.5 render the climb of dislocations and migration of high-angle grain boundaries effective (e.g. Frost and Ashby, 1982; Poirier, 1985). The shear modulus $G$ of anhydrite is about $30 \mathrm{GPa}$. Taking shear stress applied in the experiments as half of the uniaxial reference stress $\sigma$, which is between 7 and $30 \mathrm{MPa}$ (Table 1), a normalized shear stress between about $5 \times 10^{-4}$ and $1 \times 10^{-3}$ is obtained. For homologous temperatures between 0.57 and 0.69 , this is a typical normalized stress level for coarse-grained materials to deform in the regime of dislocation creep (Frost and Ashby, 1982). Finally, the stress exponent $n$ of 3.9 derived from the mechanical data is consistent with dislocation creep (e.g. Poirier, 1985; Karato, 2008).

\subsection{Extrapolation to natural strain rates}

In order to estimate the strength of polycrystalline anhydrite at low natural strain rates, the flow stress as a function of temperature is calculated for strain rates of $10^{-10} \mathrm{~s}^{-1}$ and $10^{-15} \mathrm{~s}^{-1}$, respectively, using the derived flow law (Eq. 4; Fig. 14). At a given temperature and strain rate, the flow strength of anhydrite is similar or higher than that predicted for wet quartz (Paterson and Luan, 1990). Our experiments are performed at atmospheric pressure and high temperatures, hence at essentially dry conditions, whereas the quoted flow law for quartz is based on experiments carried out at confining pressure of $300 \mathrm{MPa}$ in the presence of water. Allowance for the weakening effect of water in the dislocation creep regime as a function of confining pressure is made by introducing the fugacity term in the flow law (Hirth et al., 2001; Karato, 2008). Whether a similar weakening effect as observed for silicates could be expected for sulfates as well is not known. The high flow strength of dry anhydrite at atmospheric pressure, as demonstrated in our experiments, constitutes an intrinsic upper bound.

For comparison with previous experimental results, the flow law for fine-grained Wandflue anhydrite "AWP" derived by Müller et al. (1981) is included in Fig. 14. The large contrast in flow strength is obvious. While the data obtained in the present study represent the intrinsic strength of dry anhydrite in the dislocation creep regime with a stress exponent $n=3.9$, the experiments by Müller et al. (1981) revealed grain-size sensitivity combined with a low activation energy of $113 \mathrm{~kJ} \mathrm{~mol}^{-1}$ and a stress exponent $n=1.5$, and hence a different deformation regime.

When considering the obvious weakness of anhydrite horizons in the upper crust inferred from the natural structural record, one may speculate on deformation mechanisms activated in nature. One argument that infers dislocation creep 

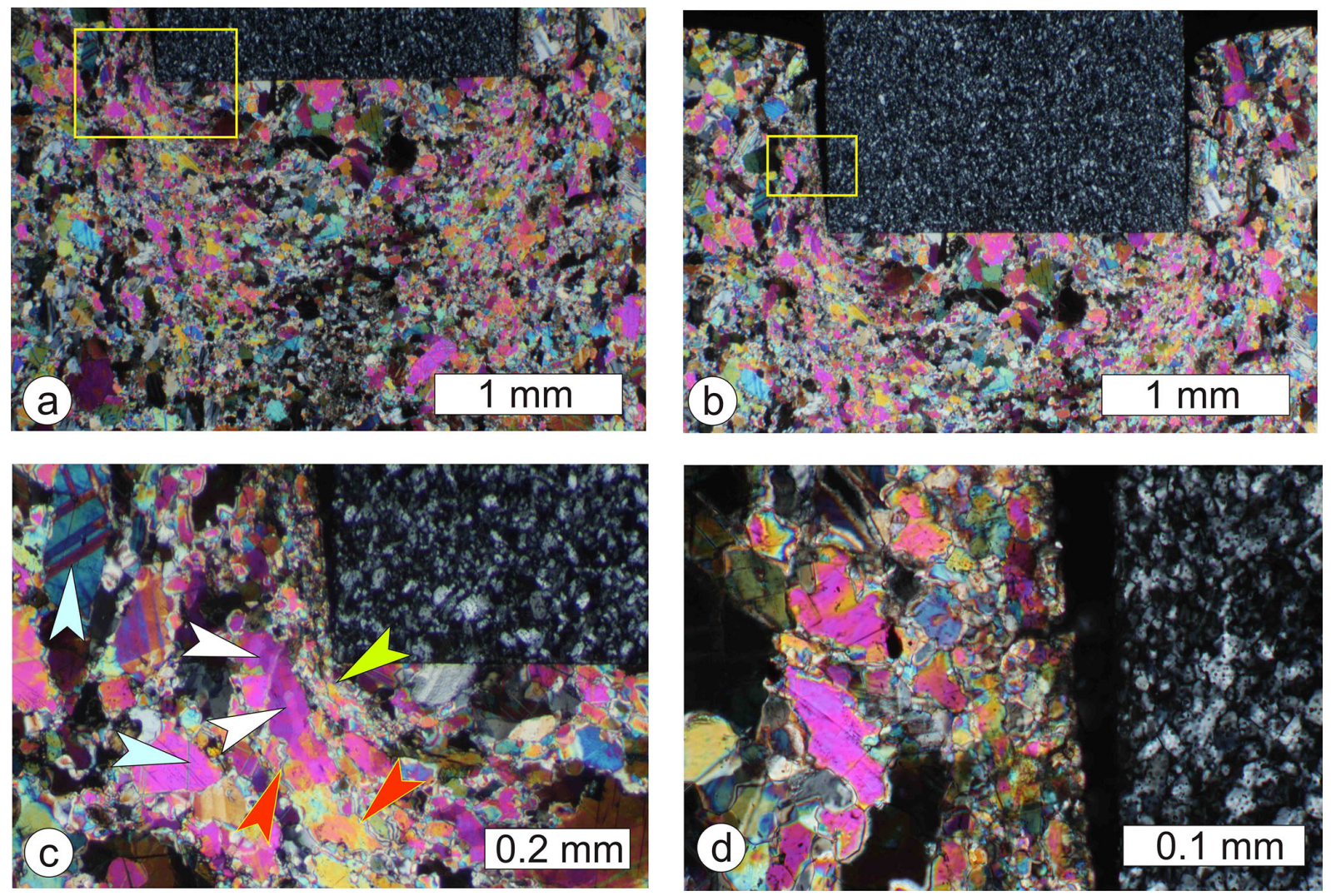

Figure 12. Microstructural details of shear zone formed near the indenter edge in high-stress experiment $\mathrm{AF} 10\left(798^{\circ} \mathrm{C}, 30 \mathrm{MPa}\right.$ reference stress). Overview (a and b) with the position of fields displayed in (c) and (d). Panel (c) - large grains aligned in the shear zone are composed of subgrains bound by low-angle grain boundaries (white arrows). High-angle grain boundaries are sutured (red arrows) and very small recrystallized grains develop near the edge of the indenter (green arrow). In the recrystallized high strain region, twins appear to be entirely absent, but are exclusively observed beyond the shear zone (left side; blue arrows). Panel (d) - fine-grained wake flanking the crevasse (cf. Fig. 9c), formed by dynamic recrystallization in the region of stress concentration at the indenter edge. No twin lamellae are discernible in the recrystallized grains.

is the pronounced CPO observed for natural anhydrite (e.g. Mainprice et al., 1993 and Hildyard et al., 2009, 2011), which is also used to infer activated glide systems. As an alternative, authors such as Godard and van Roermund (1995), Mauler et al. (2000), Wassmann et al. (2011), and Wassmann and Stöckhert (2013) have argued that a combined shape and crystallographic-preferred orientation can also result from anisotropic growth during deformation by dissolution precipitation creep. If so, microfabrics of natural anhydrite rocks highly deformed at comparatively low temperatures may alternatively have originated by dissolution precipitation creep (for recent review see Gratier et al., 2013), or a more complex combination of processes in the presence of an aqueous solution. In this case, the CPO patterns observed in naturally deformed anhydrite do not allow for the inference of activated glide systems.

Whether the flow law obtained for dry anhydrite at atmospheric pressure can be extrapolated to low natural strain rates, and whether the flow strength of dry anhydrite in the dislocation creep regime is similar to or even higher than that of wet quartz, could be tested using the microstructural record of evaporites deformed at high temperatures and containing both minerals. Unfortunately, we are not aware of a study on anhydrite-bearing rocks deformed at amphibolite or granulite facies conditions.

\subsection{Potential of indentation creep method}

Mechanical tests by high temperature indentation creep offer a number of advantages compared to other methods, although restricted to atmospheric pressure. The apparatus' design is simple. Sample preparation and experiment control are relatively straightforward. Evaluation of data is not complicated by the need to correct for friction as the contact across the mantle of the cylindrical indenter is lost by formation of the crevasse (Figs. 9b, c, 10, 11 and 12). Brittle failure and cavitation, which pose a problem in unconfined creep tests using cylindrical samples (Fig. 4a), are suppressed by the nondeviatoric component of the stress tensor beneath the indenter. According to the present results, the approach is therefore 


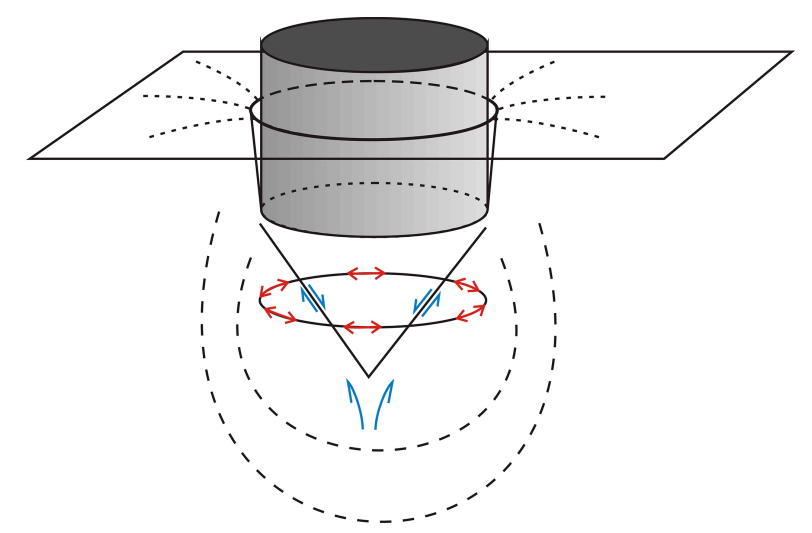

Figure 13. Scheme visualizing strain field during indentation, governed by superposition of shear (blue arrows) in a plane containing indenter axis and extension (red arrows) tangential to the perimeter of the cone when viewed in a plane normal to the indenter axis. Note that for a given volume element, stress state and incremental strain progressively change during indentation, and that the final microstructure results from stages continuously superimposed during non-coaxial deformation.

not restricted to single crystals or very fine-grained materials, though probably this depends on the type of mineral. Deformation is inhomogeneous and localized into shear zones. This allows the study of the evolution of microfabrics along strain gradients and the evaluation of the final record after non-steady-state and non-coaxial deformation. However, the complex stress and strain history at any given site (see Fig. 13) can also be regarded as a disadvantage, as it hampers a straightforward interpretation of the final microstructural record and resulting CPO patterns. Moreover, if the starting material already exhibits a complex microstructure or a preexisting $\mathrm{CPO}$, as in the present study, interpretation may become even more delicate. In future studies, comparison between experimental results and predictions from numerical simulation, which in turn require a mechanical equation of state for the material, is expected to provide insight into more complex fabric evolution in natural rocks.

\section{Conclusions}

High-temperature indentation creep tests on natural, polycrystalline anhydrite rock at atmospheric pressure were performed at temperatures between 700 and $920^{\circ} \mathrm{C}$ and net section stresses between 24 and $102 \mathrm{MPa}$, which correspond to reference stresses between 7 and $30 \mathrm{MPa}$ in uniaxial deformation of cylindrical samples. The indentation rates ranged from $10^{-11} \mathrm{~m} \mathrm{~s}^{-1}$ to $10^{-7} \mathrm{~m} \mathrm{~s}^{-1}$, corresponding to reference strain rates on the order of $10^{-9} \mathrm{~s}^{-1}$ to $10^{-5} \mathrm{~s}^{-1}$. From the indentation creep data, an activation energy $Q$ of $388 \mathrm{~kJ} \mathrm{~mol}^{-1}$ and a stress exponent $n$ of 3.9 were derived. A stress exponent of this magnitude is consistent with deformation in the dislocation creep regime, as indicated by microstruc-

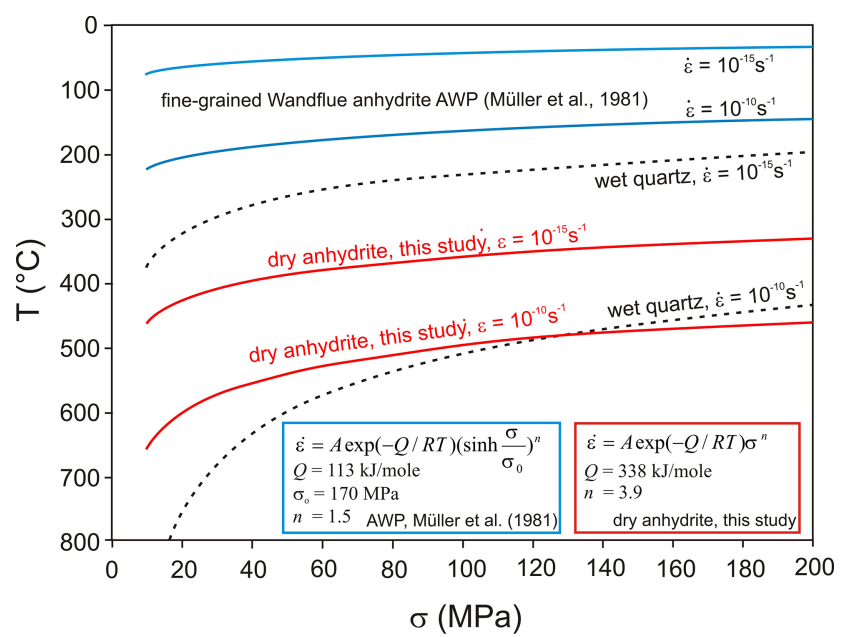

Figure 14. Flow stress of dry anhydrite as a function of temperature calculated for slow geological strain rates of $10^{-10} \mathrm{~s}^{-1}$ and $10^{-15} \mathrm{~s}^{-1}$ compared to predictions based on the experimental flow law for fine-grained Wandflue anhydrite AWP derived by Müller et al. (1981). Flow law parameters are given in the figure. A flow law for wet synthetic quartzite (Paterson and Luan, 1990) is included for reference.

tural record and expected for material flowing at homologous temperatures of 0.57 to 0.69 and normalized shear stress of $5 \times 10^{-4}$ to $1 \times 10^{-3}$.

The analysis of the microstructure close to the indenter reveals that deformation is localized in a specific region, internally well confined by the envelope of a passive cone of material underneath the indenter, and externally gradually vanishing towards the not notably affected more distant regions of the sample. In the high strain realms, the microstructure is characterized by recrystallization, recovery, and development of a crystallographic-preferred orientation by glide. At the given stress level, mechanical twinning of anhydrite is not activated, even in realms of high stress concentration.

Extrapolation of the derived flow law to slow natural strain rates yields a flow strength which is significantly higher than that predicted based on earlier experimental studies on anhydrite, which were conducted at lower temperatures, higher confining pressure, higher differential stress, and thus activating different deformation mechanisms. According to our data, the flow strength of dry anhydrite in the dislocation creep regime, at slow natural strain rates on the order of $10^{-10} \mathrm{~s}^{-1}$ to $10^{-15} \mathrm{~s}^{-1}$, would be comparable to that predicted for wet quartz. Under conditions prevailing in the deeper crust at high temperatures, anhydrite rocks therefore need not necessarily provide weak layers prone to detachment formation. Furthermore, the low flow strength of anhydrite inferred from detachment horizons bound to evaporites in the upper crust (e.g. Jordan, 1992; Jordan and Nüesch, 1989), supported by extrapolation of experimental flow laws (e.g. Müller et al., 1981) and quoted 
in summarizing diagrams (e.g. Schmid, 1982; Suppe, 1984), may be related to a contribution of deformation mechanisms other than dislocation creep, probably grain-size-sensitive dissolution precipitation creep. In this case, CPO patterns observed in anhydrite deformed in the upper crust do not allow for the inference of activated glide systems, as they may be related rather to anisotropic growth.

The results demonstrate that the comparatively simple approach of indentation creep can be successfully applied to experimental rock deformation. The non-deviatoric component of stress beneath the indenter is sufficient to prevent brittle failure in polycrystalline samples. In addition to mechanical data, the tests provide access to microstructural observations, especially along small-scale strain and strain rate gradients. The fact that the strain field and evolution of local stress and strain rate tensor do not remain uniform during progressive deformation so far precludes a quantitative assessment of microfabrics related to conditions of deformation. The flow pattern and corresponding microstructure are necessarily inhomogeneous and markedly non-steady-state. The use of finegrained material and an appropriate understanding of changing conditions during progressive deformation within a certain volume element, to be gained by numerical experiments, may overcome this drawback in the future and produce potential applications in microstructural studies beyond the traditional steady-state view.

Acknowledgements. We thank Georg Dresen and Erik Rybacki for help and advice during the installation of the creep rig, Birgit Skrotzki and Gunther Eggeler for stimulating discussions during earlier indentation projects, Wolfgang Harbott and his machine shop staff for all kinds of support, Dieter Dettmar and his colleagues for the preparation of the meticulous thin sections, and Hans-Peter Schertl for kindly providing the anhydrite specimen. Thoughtful and constructive reviews by Sandra Piazolo and Jean-Pierre Gratier are greatly appreciated and were very helpful for preparing the final version of the manuscript. Financial support by the German Science Foundation within the scope of Collaborative Research Centre 526 "Rheology of the Earth - from the Upper Crust into the Subduction Zone" is gratefully acknowledged.

Special Issue: "Rheology of the Earth - observations, laboratory experiments and numerical modelling from the micro- to the macro-scale"

Edited by: H. Thybo and W. Friederich

\section{References}

Bai, Q., Mackwell, S. J., and Kohlstedt, D. L.: High temperature creep of olivine single crystals.1. Mechanical results for buffered samples, J. Geophys. Res., 96, 2441-2463, 1991.

Barnhoorn, A., Bystricky, M., Kunze, K., Burlini, L., and Burg, J. P.: Strain localisation in bimineralic rocks: Experimental deformation of synthetic calcite-anhydrite aggregates, Earth Planet. Sci. Lett., 240, 748-763, 2005.
Bestmann, M. and Prior, D. J.: Intragranular dynamic recrystallization in naturally deformed calcite marble: diffusion accommodated grain boundary sliding as a result of subgrain rotation recrystallization, J. Struct. Geol., 25, 1597-1613, 2003.

Bruhn, D. F. and Casey, M.: Texture development in experimentally deformed two-phase aggregates of calcite and anhydrite, J. Struct. Geol., 19, 909-925, 1997.

Bruhn, D. F., Olgaard, D. L., and Dell'Angelo, L. N.: Evidence for enhanced deformation in two-phase rocks: Experiments on the rheology of calcite-anhydrite aggregates, J. Geophys. Res., 104, 707-724, 1999.

Cheng, G. C. H. and Zussman, J: Crystal structure of anhydrite, Acta Cryst., 16, 767-769, 1963.

Chiang, D. Y. and Li, J. C. M.: Impression creep of lead, J. Mater. Res., 9, 903-908, 1994.

Chopra, P. N. and Paterson, M. S.: The experimental deformation of dunite, Tectonophysics, 78, 453-473, 1981.

Chu, S. N. G. and Li, J. C. M., Impression creep - new creep test, J. Mater. Sci., 12, 2200-2208, 1977.

Chu, S. N. G. and Li, J. C. M.: Impression creep of $\beta$-tin single crystals, Mater. Sci. Eng., 39, 1-10, 1979.

Deer, W. A., Howie, R. A., and Zussman, J.: An introduction to the rock-forming minerals, Prentice-Hall, New Jersey, 1-528, 1985.

Dell'Angelo, L. N. and Olgaard, D. L.: Experimental deformation of fine-grained anhydrite - evidence for dislocation and diffusion creep, J. Geophys. Res., 100, 15425-15440, 1995.

De Paola, N., Faulkner, D. R., and Collettini, C.: Brittle versus ductile deformation as the main control on the transport properties of low-porosity anhydrite rocks, J. Geophys. Res., 114, B06211, doi:10.1029/2008JB005967, 2009.

Dorner, D. and Stöckhert, B.: Plastic flow strength of jadeite and diopside investigated by indentation hardness tests, Tectonophysics, 379, 227-238, 2004.

Dorner, D., Röller, K., Skrotzki, B., Stöckhert, B., and Eggeler, G.: Creep of a TiAl alloy: a comparison of indentation and tensile testing, Mat. Sci. Eng. A, 357, 346-354, 2003.

Frost, H. J. and Ashby, M. F.: Deformation mechanism maps - the plasticity and creep of metals and ceramics, Pergamon Press, Oxford, 1982.

Godard, G. and van Roermund, H. L. M.: Deformation-induced clinopyroxene fabrics from eclogites, J. Struct. Geol., 17, 14251443, 1995.

Gratier, J.-P.: Experimental pressure solution of halite by an indenter technique, Geophys. Res. Lett., 20, 1647-1650, 1993.

Gratier, J.-P., Renard, F., and Labaume, P.: How pressure solution creep and fracturing processes interact in the upper crust to make it behave in both a brittle and viscous manner, J. Struct. Geol., 21, 1189-1197, 1999.

Gratier, J.-P., Guiguet, R., Renard, F., Jenatton, L., and Bernard, D.: A pressure solution creep law for quartz from indentation experiments, J. Geophys. Res., 114, B03403, doi:10.1029/2008JB005652, 2009.

Gratier, J.-P., Dysthe D. K., and Renard, F.: The role of pressure solution creep in the ductility of the Earth's upper crust, Adv. Geophys., 54, 47-179, 2013.

Green, H. W. and Borch, R. S.: A new molten-salt cell for precision stress measurement at high-pressure, Eur. J. Miner., 1, 213-219, 1989. 
Griggs, D.: Hydrolytic weakening of quartz and other silicates, Geophys. J. Roy. Astr. Soc., 14, 19-31, 1967.

Handin, J. and Hager, R. V.: Experimental deformation of sedimentary rocks under high confining pressure: tests at high temperature, Am. Ass. Petrol. Geol. Bull., 42, 2892-2934, 1958.

Hangx, S. J. T., Spiers, C. J., and Peach, C. J.: The effect of deformation on permeability development in anhydrite and implications for caprock integrity during geological storage of $\mathrm{CO}_{2}$, Geofluids, 10, 369-387, 2010a.

Hangx, S. J. T., Spiers, C. J., and Peach, C. J.: Mechanical behavior of anhydrite caprock and implications for $\mathrm{CO}_{2}$ sealing capacity, J. Geophys. Res., 115, B07402 doi:10.1029/2009JB006954, 2010 b.

Haynes, W. M. (Ed.): CRC Handbook of Chemistry and Physics, 93. ed., Taylor \& Francis, Boca Raton, 2012.

Heidelbach, F., Stretton, I. C., and Kunze, K.: Texture development of polycrystalline anhydrite experimentally deformed in torsion, Int. J. Earth Sci., 90, 118-126, 2001.

Hildyard, R. C., Prior, D. J., Faulkner, D., and Mariani, E.: Microstructural analysis of anhydrite rocks from the Triassic evaporites, Umbria-March Appenines, Central Italy: An insight into deformation mechanisms and possible slip systems, J. Struct. Geol., 31, 92-103, 2009.

Hildyard, R. C., Prior, D. J., Mariani, E., and Faulkner, D.: Characterization of microstructures and interpretation of flow mechanisms in naturally deformed, fine-grained anhydrite by means of EBSD analysis, in: Deformation mechanisms, Rheology and Tectonics: Microstructures, mechanics and anisotropy, edited by: Prior, D. J., Rutter, E. H., and Tatham, D. J., Geological Society, London, Special Publications, 360, 237-255, 2011.

Hirth, G. and Tullis, J.: The brittle-plastic transition in experimentally deformed quartz aggregates, J. Geophys. Res., 99, 1173111747, 1994.

Hirth, G., Teyssier, C., and Dunlap, W. J.: An evaluation of quartzite flow laws based on comparisons between experimentally and naturally deformed rocks, Int. J. Earth Sci., 90, 77-87, 2001.

Hyde, T. H., Yehia, K. A., and Becker, A. A.: Interpretation of impression creep data using a reference stress approach, Int. J. Mech. Sci., 35, 451-462, 1993.

Jin, Z. M., Bai, Q., and Kohlstedt, D. L.: High-temperature creep of olivine crystals from 4 localities, Phys. Earth Pl. Int., 82, 55-64, 1994.

Jordan, P: Evidence for large-scale decoupling in the Triassic evaporites of northern Switzerland - an overview, Ecolog. Geol. Helv., 85, 677-693, 1992.

Jordan, P. and Nüesch, R.: Deformation structures in the Muschelkalk anhydrites of the Schafisheim-well (Jura overthrust, northern Switzerland), Ecolog. Geol. Helv., 82, 429-454, 1989.

Karato, S.-I.: Deformation of earth materials: An introduction to the rheology of solid earth, Cambridge University Press, Cambridge, 2008.

Karato, S.-I. and Wenk, H.-R. (Eds.): Plastic deformation of minerals and rocks, Rev. Mineral., 51, 1-420, 2002.

Kern, H. and Richter, A.: Microstructures and textures in evaporites, in: Preferred orientation in deformed metals and rocks: An introduction to modern texture analysis, edited by: Wenk, H.-R., 317-333, Academic Press, Orlando, 1985.
Kohlstedt, D. L. and Goetze, C.: Low-stress high-temperature creep in olivine single-crystals, J. Geophys. Res., 79, 2045-2051, 1974.

Kohlstedt, D. L., Evans, B., and Mackwell, S. J.: Strength of the lithosphere - constraints imposed by laboratory experiments, J. Geophys. Res., 100, 17587-17602, 1995.

Kolle, J. J. and Blacic, J. D.: Deformation of single-crystal clinopyroxenes. 1. Mechanical twinning in diopside and hedenbergite, J. Geophys. Res., 87, 4019-4034, 1982.

Li, J. C. M.: Impression creep and other localized tests, Mat. Sci. Eng. A, 322, 23-42, 2002.

Mackwell, S. J., Bai, Q., and Kohlstedt, D. L.: Rheology of olivine and the strength of the lithosphere, Geophys. Res. Lett., 17, 9-12, 1990.

Mainprice, D., Bouchez, J.L., Casey, M., and Dervin, P.: Quantitative texture analysis of naturally deformed anhydrite by neutrondiffraction texture goniometry, J. Struct. Geol., 15, 793-804, 1993.

Marcoux, J., Brun, J. P., Burg, J. P., and Ricou, L. E.: Shear structures in anhydrite at the base of thrust sheets (Antalya, southern Turkey), J. Struct. Geol., 9, 555-561, 1987.

Mauler, A., Bystricki, M., Kunze, K., and Mackwell, S.: Microstructures and lattice preferred orientations in experimentally deformed clinopyroxene aggregates, J. Struct. Geol., 22, 16331648, 2000.

Müller, W. H. and Briegel, U.: Experimentelle Untersuchungen an Anhydriten aus der Schweiz, Ecolog. Geol. Helv., 70, 685-699, 1977.

Müller, W. H. and Briegel, U.: The rheological behaviour of polycrystalline anhydrite, Ecolog. Geol. Helv., 71, 397-407, 1978.

Müller, P. and Siemes, H.: Festigkeit, Verformbarkeit und Gefügeregelung von Anhydrit, Tectonophysics, 23, 105-127, 1974.

Müller, W. H., Schmid, S. M., and Briegel, U.: Deformation experiments on anhydrite rocks of different grain sizes: Rheology and microfabric. Tectonophysics, 78, 527-543, 1981.

Orzol, J., Trepmann, C. A., Stöckhert, B., and Shi, G.: Critical shear stress for mechanical twinning of jadeite - an experimental study, Tectonophysics, 372, 135-145, 2003.

Paterson, M. S.: A high-pressure, high-temperature apparatus for rock deformation, Int. J. Rock Mech. Min. Sci., 7, 517-526, 1970.

Paterson, M. S. and Luan, F. C.: Quartzite rheology under geological conditions, in: Deformation mechanisms, rheology and tectonics, edited by: Knipe, R. J. and Rutter, E. H., Geological Society, London, Special Publications, 54, 299-307, 1990.

Poirier, J.-P.: Creep of crystals, Cambridge University Press, Cambridge, 1985.

Ramez, M. R. H.: Mechanisms of intragranular gliding in experimentally deformed anhydrite, Neues Jahrbuch Mineralogie Abh., 127, 311-329, 1976.

Renner, J., Stöckhert, B., Zerbian, A., Röller, K., and Rummel, F.: An experimental study into the rheology of synthetic polycrystalline coesite aggregates, J. Geophys. Res., 106, 19411-19429, 2001.

Riccardi, B. and Montanari, R.: Indentation of metals by a flatended cylindrical punch, Mat. Sci. Eng. A 381, 281-291, 2004. 
Ross, J. V., Bauer, S. J., and Hansen, F. D.: Textural evolution of synthetic anhydrite-halite mylonites, Tectonophysics, 140, 307326, 1987.

Rowe, K. J. and Rutter, E. H.: Paleostress estimation using calcite twinning - experimental calibration and application to nature, $\mathrm{J}$. Struct. Geol., 12, 1-17, 1990.

Rutter, E. H.: Experimental study of the influence of stress, temperature, and strain on the dynamic recrystallization of Carrara marble, J. Geophys. Res., 100, 24651-24663, 1995.

Rybacki, E. and Dresen, G.: Dislocation and diffusion creep of synthetic anorthite aggregates, J. Geophys. Res. 105, 26017-26036, 2000.

Rybacki, E., Renner, J., Konrad, K., Harbott, W., Rummel, F., and Stöckhert, B.: A servohydraulically-controlled deformation apparatus for rock deformation under conditions of ultra-high pressure metamorphism, Pure Appl. Geophys., 152, 579-606, 1998.

Sarg, J. F.: The sequence stratigraphy, sedimentology, and economic importance of evaporite carbonate transitions: a review, Sediment. Geol., 140, 9-34, 2001.

Schmid, S. M.: Microfabric studies as indicators of deformation mechanisms and flow laws operative in mountain building, in: Mountain Building Processes, edited by: Hsü, K. J., Academic Press, London, 95-110, 1982.

Schmid, S. M., Boland, J. N., and Paterson, M. S.: Superplastic flow in finegrained limestone, Tectonophysics, 43, 257-291, 1977.

Schorn, A. and Neubauer, F.: Emplacement of an evaporitic mélangenappe in central northern calcareous Alps: Evidence from the Moosegg klippe, Austria, Austrian J. Earth Sci., 104, 22-46, 2011.

Skrotzki, B., Rudolf, T., and Eggeler, G.: Creep behavior and microstructural evolution of a near- $\gamma$-TiAl alloy with duplex microstructure, Z. Metallkd., 90, 393-402, 1999.

Spry, A.: Metamorphic textures, Pergamon Press, Oxford, 1969.

Suppe, J.: Principles of structural geology, Prentice Hall, 1-560, 1984.

Tasnádi, P., Juhász, A., Chinh, N., and Kovács, I.: Theoretical description of the deformation taking place in an impression test, Res. Mech., 24, 335-347, 1988.
Trepmann, C. A. and Stöckhert, B.: Mechanical twinning of jadeite - an indication of synseismic loading beneath the brittle-plastic transition, Int. J. Earth Sci., 90, 4-13, 2001.

Tröger, W. E.: Optische Bestimmung der gesteinsbildenden Minerale, Teil 1, Bestimmungstabellen, Schweizerbart'scheVerlagsbuchhandlung, 1-188, 1971.

Tullis, T. E.: The use of mechanical twinning in minerals as a measure of shear-stress magnitudes, J. Geophys. Res. 85, 6263-6268, 1980.

Tullis, T. and Tullis, J.: A review of high pressure experimental deformation techniques, Am. Geophys. Un. Monogr., 36, 297-324, 1986.

Wang, Z., Dresen, G., and Wirth, R.: Diffusion creep of finegrained polycrystalline anorthite at high temperature, Geophys. Res. Lett., 23, 3111-3114, 1996.

Wassmann, S. and Stöckhert, B.: Rheology of the plate interface - Dissolution precipitation creep in high pressure metamorphic rocks, Tectonophysics, 608, 1-29, 2013.

Wassmann, S., Stöckhert, B., and Trepmann, C. A.: Dissolution precipitation creep versus crystalline plasticity in high-pressure metamorphic serpentinites, in: Deformation mechanisms, Rheology and Tectonics: Microstructures, mechanics and anisotropy, edited by: Prior, D. J., Rutter, E. H., and Tatham, D. J., Geological Society, London, Special Publications, 360, 129-149, 2011.

$\mathrm{Yu}, \mathrm{H}$. and $\mathrm{Li}, \mathrm{J} .:$ Computer-simulation of impression creep by finite-element method, J. Mater. Sci. 112, 2214-2222, 1977.

Yu, H., Imam, M., and Rath, B.: Study of the deformation-behavior of homogeneous materials by impression tests, J. Mat. Sci., 20, 636-642, 1985.

Yue, Z. F., Eggeler, G., and Stöckhert, B.: A creep finite element analysis of indentation creep testing in two phase microstructures (particle/matrix- and thin film/substrate-systems), Comput. Mat. Sci., 21, 37-56, 2001.

Zaafarani, N., Raabe, D., Singh, R. N., Roters, F., and Zaefferer, S.: Three-dimensional investigation of the texture and microstructure below a nanoindent in a $\mathrm{Cu}$ single crystal using 3D EBSD and crystal plasticity finite element simulations, Acta Material., 54, 1863-1876, 2006. 